\title{
LA PARTICIPACIÓN PRIVADA EN LA GESTIÓN DE LA SALUD PÚBLICA
}

\author{
Sebastián Flores Díaz \\ Universidad Autónoma de Madrid, España \\ sfloresabogado@gmail.com
}

\section{RESUMEN}

El artículo analiza los contratos entre el sistema público de salud y proveedores privados. En específico, se estudia la participación del sector privado en el sistema público de salud y cómo se acude a mecanismos contractuales para incorporarlos en ellos, una tendencia que a nivel internacional cobra mayor fuerza. En el diseño contractual se presentan dos grandes tendencias. La primera de ellas se crear condiciones de mercado en la prestación de las atenciones de salud, en la que el privado compite con entes públicos por los mismos recursos. La segunda tendencia es plantear la participación de prestadores privados como colaboradores del sector público, caso en el que los contratos serán mecanismos articuladores de una red asistencial. El artículo muestra que la segunda tendencia es la que se aplica en el caso chileno. Se argumenta que los convenios realizados por los servicios de salud y sus entes dependientes, han tendido a crear una suerte de cuasimercado de prestaciones de salud. A la vez, se analiza cómo los contratos celebrados por Fonasa, que han articulado una red público privada con resultados positivos.

Palabras clave: Derecho administrativo, Contratación pública, Asociaciones público-privadas, Sistemas de salud, Chile. 


\title{
PRIVATE PARTICIPATION IN THE MANAGEMENT OF PUBLIC HEALTH CARE
}

\begin{abstract}
The article analyzes contracts between the public health system and private providers. Specifically, it examines the private sector's participation in the public health system and how the latter uses contractual mechanisms to incorporate private providers, a trend that is gaining ground internationally. There are two major trends in contract design. The first creates market conditions in the provision of health care under which private players compete with public entities for the same resources. Under the second, private providers are viewed as collaborators of the public sector and contracts serve as mechanisms for articulating a health care network. The article shows that the second trend is found in Chile. It argues that the agreements reached by health services and their dependent bodies have tended to create a kind of quasi-market in health care. At the same time, it analyzes how contracts signed by the National Health Care Fund (FONASA) have articulated a public-private network with positive results.
\end{abstract}

Keywords: Administrative law, Public contracts, Public-private partnerships, Health systems, Chile. 


\section{INTRODUCCIÓN}

Uno de los grandes desafíos de los sistemas de salud es determinar la participación que le corresponde en ellos al sector privado. Su presencia en el financiamiento, aseguramiento y provisión de prestaciones es innegable, y cada día adquiere mayor importancia como productor y oferente de servicios (Carvajal 2012). Sin embargo, esta participación en los servicios sanitarios públicos genera un debate en torno a dos polos claros: 1) la mayor eficiencia que ofrecerían los privados; y 2) el ánimo de lucro que podría inducirlos a distorsionar los precios de sus atenciones y, de este modo, defraudar las finanzas públicas (Meneu y Urbanos 2018). Específicamente, es relevante la provisión de atenciones clínicas que brindan los privados al sector público sanitario cuestión que suele asociarse a una privatización de la sanidad pública (Sánchez-Martínez, Abellán-Perpiñán y Oliva-Moreno 2014). Asociado a esto, aparece la normativa de contratos del sector público pues la participación de prestadores privados frecuentemente se realiza mediante fórmulas contractuales (Cantero 2018, Rodríguez 2019) las que se ven como una forma velada de privatización (Perrot 2006b).

La forma de participación de proveedores privados en atenciones clínicas para el sector público está estructurada en el artículo 3 del Decreto Ley $\mathrm{N}^{\circ}$ 2.763 y en el Decreto con Fuerza de Ley $N^{\circ} 36 / 80$. Ambos se enmarcan en una política de construcción y ampliación de un sector privado sanitario empleando la infraestructura pública (Moraga Cortés, Bahia Coelho, y Prada Sanabria 2018). Esta sería la normativa imperante hasta la implementación de la reforma que creó el Plan de Acceso Universal de Garantías Explícitas (AUGE) y las GES, que coincidió con la entrada en vigencia de la Ley de Compras Públicas. Desde entonces, la participación del sector privado ha adquirido la forma jurídica de una compra de servicios, cuestión que genera una dicotomía peculiar pues, por un lado, permite articular redes público-privadas en los diferentes servicios de salud, pero también ha generado un cuasimercado de servicios de profesionales de medicina en atenciones especializadas. Dicho de otro modo, la evidencia que se expone indica que los prestadores institucionales usan los contratos de compras para colaborar con la red de salud, mientras que los prestadores individuales (los profesionales de la salud) se constituyen como entes privados para escapar de las regulaciones y remuneraciones establecidas en las leyes, provocando una escasez de atenciones en el sector público, lo que les permite aumentar el precio de sus servicios.

La discusión está en el uso de contratos como mecanismos de participación del sector privado en tareas que la legislación define como pública, en este caso, las atenciones en el Sistema Nacional de Servicios de 
Salud (SNSS). La atención del mundo político suele estar centrada en los convenios del Fondo Nacional de Salud (Fonasa), a pesar de que ellos se diseńan e implementan como una alianza de largo tiempo. Se suele obviar, a pesar de las auditorías de la Contraloría General de la República (CGR), los contratos entre los entes del SNSS con sus profesionales dependientes, que constituidos como personas jurídicas privadas venden sus servicios a un costo más caro de lo que se contempla en la legislación que regula los estipendios de esos profesionales.

Entonces es necesario reflexionar respecto del uso de los contratos públicos en el sector salud, específicamente como las autoridades que los diseñan deciden quienes son los prestadores privados con los que celebrarán estos convenios y en segundo lugar como definirán la participación de estos en el SNSS. En este último caso, si se trata solo de compras de prestaciones para reducir listas de espera o de una alianza continúa en el tiempo. Esta reflexión también genera otra interrogante acerca de si la Ley de Compras Públicas es la más adecuada para regular los convenios del sector salud, pues termina reduciendo cualquier acuerdo entre el sector público y los privados a un contrato de contrato de suministro (Camacho 2008), es decir, un convenio para "la adquisición, arrendamiento financiero o arrendamiento, con o sin opción de compra, de productos o bienes muebles" (Muñoz Machado 2017: 624). La aplicación de esta ley se explica principalmente por la falta de otras leyes (Barra y Celis 2015).

En el presente trabajo se presenta la participación del sector privado en el sistema público de salud y cómo se acude a mecanismos contractuales para incorporarlos en ellos, una tendencia que a nivel internacional cobra mayor fuerza (Perrot 2006a). Sin embargo, en el diseño contractual se presentan dos grandes tendencias. La primera de ellas se crear condiciones de mercado en la prestación de las atenciones de salud, en la que el privado compite con entes públicos por los mismos recursos. La segunda tendencia es plantear la participación de prestadores privados como colaboradores del sector público, caso en el que los contratos serán mecanismos articuladores de una red asistencial.

Como se muestra a continuación, la segunda tendencia es la que se aplica en el caso chileno. En él, por un lado, están los convenios realizados por los servicios de salud y sus entes dependientes, que han tendido a crear una suerte de cuasimercado de prestaciones de salud -abordando el asunto de las sociedades médicas-, y por otro, los contratos celebrados por Fonasa, que han articulado una red público privada con resultados positivos. 
El artículo sigue con cuatro apartados. El primero presenta la participación del sector privado en los sistemas de salud. El segundo apartado aborda el paso de la contractualización de las relaciones en el sector salud y su derivación en un sistema de compras públicas basado cuyo objeto era la construcción de un mercado competitivo. En tercer lugar, se abordará el caso chileno, en el por un lado los convenios realizados por los servicios de salud y sus entes dependientes han tendido a crear una suerte de cuasi mercado de prestaciones de salud - abordando el asunto de las sociedades médicas- $y$, por otro, los contratos celebrados por Fonasa han articulado una red público privada con resultados positivos. En el apartado final se ofrecen conclusiones en las cuales se discute las experiencias de Fonasa y los servicios de salud y se realizan propuestas en este sentido.

\section{LA PARTICIPACIÓN PRIVADA EN EL SISTEMA PÚBLICO DE SALUD}

Una gran mayoría de los sistemas de salud admite la participación de prestadores privados como colaboradores del sector público (Meneu y Urbanos 2018). Una de las dimensiones del concepto de sistema de salud se refiere a la articulación de centros y servicios sanitarios o en forma de red capaz de responder a un amplio espectro de programas de salud (Repullo Labrador 2014), independiente de si el titular de los mismos es el sector público o el privado. Incluso en las definiciones del concepto de salud pública se contempla este aspecto. Muńoz Machado (2017) indica que un sistema de salud es "conjunto integrado de organizaciones y servicios ya sean públicos o privados, de carácter sanitario, administrativo o económico dirigidos a promover la salud de las personas", definición que está en sintonía con los parámetros que entrega la Organización Mundial de la Salud (OMS) (2005), que ańade la necesidad de que los tratamientos y servicios respondan a las necesidades de la población y tengan un financiamiento justo.

En este sentido, Zúñiga Fajuri (2007) sugiere que el objetivo del sector público sanitario no es ofrecer prestaciones de salud a toda la población de forma gratuita, sino garantizar que nadie quede sin cuidados médicos ante una enfermedad, o deba caer en la pobreza para costear su tratamiento.

\section{EL PAPEL DEL SECTOR PRIVADO EN LOS SISTEMAS DE SALUD}

La presencia del sector privado puede darse en cualquiera de los procesos fundamentales de los sistemas de salud: financiamiento, regulación y la provisión de prestaciones (Wendt, Frisina y Rothgang 2009). Su 
participación se distinguirá si operan con una mentalidad pública o por el contrario si operan con una mentalidad orientada al mercado (Cortez 2015). Esta distinción cobra especial relevancia en la clasificación de sistemas de salud unificados y pluralistas, según la cual, en los primeros solo un actor se hace cargo de la provisión del cuidado sanitario, mientras que en los segundos entes públicos y privados intervienen. Para Zúñiga Fajuri (2007), en los sistemas unificados prima una idea de justicia igualitarista por sobre la utilidad, mientras que en los segundos prima la eficiencia y la cobertura por sobre las consideraciones de justicia. En ambos sistemas participan actores privados, pero con diferentes énfasis. Por un lado, en los sistemas unificados el privado tiende a asumir un rol de colaborador, mientras que en los pluralistas existe una pseudo competencia entre proveedores públicos y privados para captar pacientes.

El proceso de financiamiento es uno de los aspectos claves en los sistemas sanitarios, pues en él se juega gran parte del derecho de protección de la salud ya que determina si un sistema podrá dar protección a quienes no pueden pagar o si alguien quedaría en la pobreza a causa de su padecimiento (Pérez Gálvez 2015, Adhanom Ghebreyesus 2017). Este es el fundamento de los servicios públicos de salud (Villar Rojas 2020)

El proceso de financiamiento genera arduos debates entre quienes son partidarios de emular sistemas europeos, como el británico o el español, financiados por impuestos y con cobertura universal y gratuita (Laurell 2012, 2016), y quienes defienden los sistemas basados en el aseguramiento como mecanismo de ampliación de la cobertura (Báscolo et al. 2018). Esta discusión puede soslayarse por dos razones. La primera de ellas es que los sistemas sanitarios latinoamericanos no son equivalentes a los que han prevalecido en las grandes economías de la Organización para la Cooperación y el Desarrollo Económicos (OCDE), como lo explica Barba Solano (2018). La segunda es que, en último término, el financiamiento siempre lo realiza el ciudadano, pues ni los sistemas financiados por impuestos ni por seguros tienen la capacidad de generar recursos por sí mismos, sino que siempre será el usuario que, de una forma u otra, contribuirá a financiar el sistema (Villalobos Dintrans 2016, BecerrilMontekio, Reyes y Annick 2011). Sin embargo, hay que enfatizar que la mejor solución será juntar los aportes de todos los usuarios para contribuir de forma solidaria a financiamiento (Repullo Labrador 2014).

En relación con la regulación, se entiende que es una función propia del poder político bajo la denominación de autoridad sanitaria, relacionado con el ejercicio de actos de soberanía o de autoridad. 
Finalmente, la provisión de esos servicios está relacionada con quien presta efectivamente las atenciones de salud. Tanto el sector público como el sector privado ofrecen servicios de salud, y cuesta entender si se trata de colaboradores, competidores o actúan de forma independiente.

Se pueden distinguir tres grandes procesos de reforma a los sistemas de salud en América Latina, todos ellos impulsados y dirigidos por los organismos financieros internacionales, como el Fondo Monetario Internacional, el Banco Interamericano de Desarrollo o el Banco Mundial (Barba Solano 2012).

El primer proceso de reformas apuntó a descentralizar los sistemas públicos de salud para liberar fondos y de este modo, que los gobiernos pagaran sus deudas externas. Es en el segundo proceso de reformas en la década de 1990 que potencia el rol de la economía (Martínez Lillo y Rubio Apiolaza 2016), en los que se buscó la combinación del sector público y privado, se puso el énfasis en la competencia entre diferentes actores para promover la eficiencia (Barba Solano 2012).

El segundo proceso de reformas tenía por objeto mercantilizar el aseguramiento y la provisión de servicios de salud, introduciendo competencia entre los diferentes actores y generando cuasimercados sanitarios. El papel del Estado está en brindar atenciones de salud a los más pobres y el resto de la población debería pagar por ella (Banco Mundial 1987, 1993). Junto con este cambio de eje, se propone que el sector privado asuma un rol más activo en la provisión de servicios de salud. El uso de los contratos entre el sector público y el privado tenía por objeto crear condiciones de mercado en la salud (Benatar et al. 2018), basadas en compras de atenciones de salud por parte del Estado a prestadores privados (Laurell y Herrera 2010).

Dentro de este proceso se separó la provisión de atenciones de salud, que sería brindada por prestadores públicos o privados, del pago de estas, que ahora se entendería como una compra de servicios. Esta separación fue el inicio de una gestión contractual de la sanidad pública (Sánchez de León 2004: 108, Albuquerque, Morais y Lima 2015). Estos procesos fueron comunes en casi todos los sistemas sanitarios lo que condujo a un proceso de convergencia (Repullo Labrador 2014) y, en algunos casos, trajo una mejora en la eficiencia (Escoval, Ribeiro y Matos 2010).

En este proceso se masificó el uso de conceptos importados desde la economía, como el de cuasimercado para rediseñar el sistema sanitario como un modelo de racionalidad económica (Erazo 2015, Cantero 
Martínez 2018). En el caso de los prestadores públicos se introducía un precio negociado o simulado para mejorar la eficiencia y calidad, mientras que, con los proveedores privados, el precio negociado sustituía al de mercado, que podía estar fuera del alcance de los usuarios (Sojo 2000, 2001). Vale decir, a través de estos contratos el Estado asume un rol de intermediario entre el proveedor de servicios y el usuario, y en el caso de prestadores privados, adquiere sus servicios mediante la licitación pública. Los elementos del mercado están en lado de la oferta, pues la demanda está determinada por el presupuesto público (Salas 2017).

También cobran fuerza los conceptos de función de compra de prestaciones sanitarias o función de compra de servicios de salud, como mecanismos de incentivos de ahorro en materia de prestaciones sanitarias. Llevar el pago de prestaciones de salud a compras tiene por objeto pasar de los mecanismos de pago retrospectivos en los que se cubren todos los costos - sin incentivos para contener los gastos y producir una cantidad óptima de servicios- a mecanismos prospectivos, en los que se ensayan diferentes fórmulas para que el prestador ahorre (Castro Jaramillo 2014: 22).

La función de compra se refiere al mecanismo de transferencia de fondos a los prestadores de atenciones (OMS 2000, Sánchez de León 2004: 105), es decir, el modo en que el ente responsable de la recaudación financiera del sistema de salud pagará a los proveedores por las atenciones realizadas. Para la economía de la salud, los mecanismos de pago son contratos que llevan implícitos distintos incentivos (González López-Valcarcel 2006, Castro Jaramillo 2014: 22). En un sentido jurídico, no es claro que estos pagos sean una compra. En el caso de los prestadores públicos se trata de transferencias. En el caso de los prestadores privados sería una compra de suministros o un acuerdo de colaboración. En ambos, se trata de contratos en el sentido jurídico

Finalmente hay un tercer proceso de reformas, inspirado en la concepción de Estado garante, en los cuales la autoridad pública debe garantizar el acceso a determinados derechos y servicios sociales, siendo indiferente si los presta ella o lo hace el sector privado supervisado por la Administración del Estado. Con esto se mantiene una tendencia a externalizar o tercerizar las actividades estatales sociales (Labaure Aliseris 2000).

Una cuestión que caracteriza a las reformas sanitarias en América Latina es su debilidad normativa. Se suelen redactar textos constitucionales y legales con grandes declaraciones que consagran derechos sin que ellas se 
traduzcan en normas que operativicen procedimientos para el ejercicio de los mismos (Barba Solano 2012).

\section{Notas SOBRE LA DISCUSIÓN DE LA PRIVATIZACIÓN DE LA GESTIÓN SANITARIA}

En relación con la gestión sanitaria por parte del sector privado, ella suele asociarse al concepto de una eventual privatización (Perrot 2006b, Sánchez-Martínez, Abellán-Perpiñán y Oliva-Moreno 2014). Este aspecto es problemático por el carácter económico de la prestación de atenciones de salud junto con su dimensión solidaria. Para algunos, la salud podría calificarse como un servicio privado de interés público (Rojas Calderón 2018, Moraga Klenner 2019) lo que la llevaría a estar bajo supervisión administrativa. Otros defienden su carácter público, a pesar de su dimensión económica, pues el carácter económico queda en segundo plano ante la dimensión social de esta actividad dirigida a garantizar un derecho fundamental relacionado con la vida y la integridad (Domínguez Martín y Chichilla Peinado 2019). Domínguez Martín justifica la exclusión de los aspectos económicos en la prestación de servicios sanitarios por parte del sector privado, pues se trata de una actividad dirigida a garantizar derechos fundamentales, siendo una manifestación de los principios de cohesión social y solidaridad. En efecto, encuadra los servicios sanitarios en la categoría del derecho europeo de servicio de interés general no económico, que se caracterizan por una financiación primordialmente pública y que persiguen objetivos sociales con efectos redistributivos (2019). Sin embargo, este aspecto abre, al menos, dos discusiones que no están zanjadas del todo.

La primera discusión se refiere al modelo sanitario que adopta cada país, y que, por regla general, se puede encontrar en el precepto constitucional y que determinará los fundamentos doctrinales e ideológicos en los que cimenta el sistema sanitario de cada país (PIPP 2011). Desde el punto de vista libertario, Lemieux (2015) argumenta en contra la labor distributiva de los sistemas sanitarios, pues el único valor importante es la libertad individual y de elección. El sistema de salud de Estados Unidos se construye de esta manera. Quienes no pueden pagar tienen como alternativa la beneficencia (Zúñiga Fajuri 2011). Pero incluso argumentos basados en la libertad y la igualdad de oportunidades pueden ser utilizados para justificar la existencia de un sector público que garantice un mínimo de prestaciones sanitarias (Zúniga Fajuri 2010).

El segundo debate es sobre el contenido del derecho de protección de la salud en cada ordenamiento que mandata al Estado a construir los 
sistemas, instituciones y procedimientos para satisfacer las necesidades de la población (Alonso-Olea y Medina 2016). Aunque el análisis de la configuración del derecho de protección de la salud excede este trabajo, es necesario tener presente unas nociones para el desarrollo de los sistemas públicos de protección y cómo participará el sector privado en ellos.

Si se compara el artículo 43 de la Constitución Española con el artículo $19 \mathrm{~N}^{\circ} 9$ de la Constitución Política de la República de Chile aparecen diferencias en que garantiza cada Estado cuando indica que asegura la protección de la salud. Mientras el artículo 43 de la Constitución Española establece el derecho de protección de la salud, encomendando a los poderes públicos organizar y tutelar la salud pública a través de medidas preventivas y servicios necesarios, el artículo $19 \mathrm{~N}^{\circ}$ 9, de la Constitución Política de la República chilena protege la libertad acceso a las prestaciones de salud y la libertad de elección del sistema público o privado, dando una visión propia de un sistema neoliberal (Comes s.f.), en la que la salud es un bien de consumo que debe ser pagado y el Estado focalizará su actuación en quienes no pueden hacerlo. En este caso, el constituyente apostó porque el sector privado fuese el principal y la actuación estatal tuviese un papel residual focalizado en los más pobres, aunque no consideraron que aproximadamente el $40 \%$ vivía bajo la línea de la pobreza al implementarse el sistema de salud (Reichard 1996). La realidad fue más fuerte, pues los más pobres y la clase de los vulnerables son la mayoría de la población. En Chile, el $80 \%$ de la población es beneficiario del sistema público (Fonasa s.f.), mientras que solo un 19 es beneficiario de las instituciones de salud previsional, Isapres, (Superintendencia de Salud s.f.). Desde la década de 2000 se aprecia una tendencia de la población a afiliarse a Fonasa.

Otros caso similares al modelo constitucional chileno es el artículo 49 de la constitución colombiana de 1991 o el artículo 11 de la constitución peruana. Sin embargo, existen otros casos latinoamericanos en que el precepto constitucional mandata al Estado a articular sistemas públicos de salud, como ocurre en los artículos 23 II y 196 a 200 de la constitución brasileña o el artículo 73 de la constitución de Costa Rica. En estos casos, el Estado asume la titularidad de la prestación de los servicios sanitarios. En el caso costarricense se trata de un sistema unificado basado en un seguro público que puede incorporar a privados como colaboradores El artículo 199 de la constitución brasileña admite expresamente la participación privada de forma complementaria mediante un contrato de derecho público. Esto permitió una larga tradición de contratación pública en salud (Becerril Montekio, Medina y Aquino 2011, Franco-Giraldo 2014). 


\section{BREVE REVISIÓN DE ESTE PROCESO EN LATINOAMÉRICA}

Tal como se mencionó en el apartado anterior, los países latinoamericanos ensayan diferentes fórmulas de participación del sector privado en el sistema público. Priman los sistemas pluralistas en los que participan privados en la provisión y aseguramiento de la salud en contraposición a los sistemas unificados en los que un actor (frecuentemente el Estado) se hace cargo de la asistencia sanitaria (Zúńiga Fajuri 2007) y el privado adquiere un rol de colaborador en aquellas situaciones en que el Estado no puede hacerse cargo. Esto genera problemas como duplicidad de cobertura para algunos y ausencia para otros, así como la selección de pacientes, descoordinación entre las tareas de salud pública, baja prevención y tratamiento de enfermedades, y elevados costos de atención que conllevan a inequidades en el acceso y en la calidad, entre otros problemas (Medici 2004). Junto con ello, la gran mayoría de las reformas a los sistemas de salud en la región se basó en incentivos económicos en el aseguramiento y la promoción de la competencia como factores dinamizadores de transformación del resto del sistema (Báscolo et al. 2018).

González López-Valcarcel (2019) esboza una explicación de esta interacción con el concepto de latinoamericanización de la sanidad (salud) pública, que da cuenta de las preferencias de los diferentes estratos de la sociedad respecto de los prestadores públicos o privados. Mientras las clases altas prefieren al sector privado como prestador, los sectores medios intentan acceder a prestadores privados abandonando los sistemas públicos, salvo en los casos catastróficos, y los sectores de menores ingresos quedan cautivos en el sistema público.

De esta descripción se infiere que, en relación con los sectores de mayores ingresos, el sector privado sería indiferente del sector público, a menos que se trate de enfermedades catastróficas o de alto costo (situación en la cual los usuarios optaría por el sistema público). La competencia real se da en los sectores medios y respecto de la atención primaria y especializada de salud. Hay que tener presente que en América Latina no existe una clase media similar a la europea. Estefanía (2016) explica que, en lugar de sectores medios, es más preciso hablar de la clase de los vulnerables, que no contarían con la seguridad económica con la que sí cuenta una verdadera clase media. Los vulnerables son el grupo social más extendido de la región, pues representa el $38 \%$ de la población. Ellos preferirían la salud privada por sobre la pública, a menos que se enfrenten a una enfermedad de alto costo que en muchos casos puede significar el retorno a la pobreza. 
En relación con los sectores de menos ingresos, el prestador privado actúa como un colaborador. Esto se explica por el rápido crecimiento del sector privado en salud en contraposición a las obligaciones de reducción del gasto público en salud. Además, los privados amplían la cantidad de servicios que se pueden ofrecer utilizando un óptimo de producción.

El mecanismo jurídico de asociación entre el sistema público y los prestadores privados ha sido el acuerdo contractual (OPS 2010, FrancoGiraldo 2014). Este aspecto es relevante porque el segundo y tercer proceso de reformas en los sistemas sanitarios en América Latina coincide con la implementación de legislación de contratación pública. Ambos procesos fueron parte de las modernizaciones del Estado (Benavides y Moreno Cruz 2016). Sin embargo, el uso de estos contratos fue diferente en los sistemas unificados - como Brasil y Costa Rica-, que los concibieron como convenios de asociación, respecto de los sistemas pluralistas -como es el caso de Chile o Colombia- en los que se usan como compra de servicios y, en algunos casos, como mecanismo de externalización (Medici 2004).

Este aspecto está relacionado con las dos concepciones que existen en América Latina de la contratación administrativa. Por un lado, están las compras públicas, que son contratos sinalagmáticos en los que se ofrecen bienes y servicios a la Administración a cambio de una remuneración proveniente de los recursos presupuestales y, por otro lado, están los modelos de participación privada que se enmarcan como contratos conmutativos (Benavides 2016)

\section{DE LA CONTRACTUALIZACIÓN DE LAS RELACIONES SANITARIAS A LA CONTRATACIÓN PÚBLICA SANITARIA}

\section{EL IMPULSO HACIA LA CONTRACTUALIZACIÓN POR PARTE DE LA OMS}

En el informe mundial de la salud del año 2000, la OMS (2000) abogó por una gestión contractual en los sistemas de salud, pues considera que la administración de los servicios públicos jerarquizados y burocráticos no es eficiente. Aunque no es partidaria de una gestión basada solo en compra de servicios, que podría transformarse en un mero pago de facturas (2000).

Según explica Perrot (2006b), en 2001 la OMS clasificó los diferentes acuerdos contractuales en tres grupos: 1) la delegación de responsabilidad; 2) la compra de servicios; y 3) la cooperación. En relación con la delegación de responsabilidad, sería una concesión de servicio público, en la cual la autoridad asume un rol de supervisión de la actividad. Respecto de las compras de servicios, en principio se acudía al mercado para comprar 
servicios no médicos. Sin embargo, hubo un avance de la contractualización provocó que las compras se utilizaran para la realización prestaciones clínicas. Finalmente, están los acuerdos de cooperación que se caracterizan por las posibilidades de sinergia entre el sector público y los privados que colaboran en un objetivo común. Este tipo de acuerdos suele aplicarse a relaciones de redes asistenciales o acuerdos concertados

A pesar de la importancia del asunto, no hay estudios acabados sobre este proceso de contractualización de las relaciones entre prestadores y los entes financieros de los sistemas sanitarios. Hay pocos artículos académicos (Moreo Marroig 2018, García Pérez 2018) que suelen reconducir la discusión a la adquisición de medicamentos o a temas relativos a los seguros privados de salud. Se constata que la opacidad de los mecanismos de compras públicas en materia sanitaria es una constante que provoca problemas de eficiencia, precios mayores, licitaciones mal preparadas, separación de las mismas, entre otros problemas (Carnota Lauzán 2017), cuestión que resulta contradictoria con los principios declarados por las diferentes legislaciones sobre contratación pública como la transparencia, probidad, igualdad entre los oferentes entre otros entre otros.

Hay que considerar que la asistencia sanitaria es una actividad prestacional, es decir, no supone el ejercicio de potestades públicas, por lo que tampoco es necesario que en todos los casos se gestione directamente por el sector público (Torno Mas 2016). Lo que existe es una titularidad pública justificada en la satisfacción de necesidades públicas (Camacho 2010, Parejo 2004).

\section{LOS CONTRATOS DEL SECTOR PÚBLICO SANITARIO CON PRESTADORES PRIVADOS: LOS CUASIMERCADOS}

El proceso de reformas al sector salud impulsado por los organismos financieros internacionales tuvo por objeto generar un mercado interno de servicios de salud que estimulen la competencia y, de este modo, se produzca la eficiencia (Katz y Miranda 1994, Cantero Martínez 2018). Es clave que los mismos contratos generen esa competencia al momento de la licitación (Sánchez-Martínez et al. 2014). Estos procesos se denominaron reformas neoliberales (Ugalde y Homedes 2005a). En ellas se pretendió reemplazar al sector público por prestadores privados.

Lo que caracteriza a estos cuasimercados es que el Estado asume un rol de intermediario entre el operador privado y el usuario, adquiriendo bienes mediante la licitación pública para que los usuarios puedan elegir un operador de acuerdo a sus preferencias (Sojo 2000). Como los postulados 
neoclásicos predicaban una retirada del Estado, se pretendía también que esta compra la realizaran aseguradores privados.

Los elementos del mercado están en el lado de la oferta, pues la demanda está determinada por la autoridad pública mediante licitación (Salas 2017). Los acuerdos se denominan contratos-programas (Sánchez Martínez et al. 2014: 77) o compromisos de gestión (Sojo 2001: 141), que tienen por objeto abandonar los pagos por actividad y pasar sistemas de pagos por desempeño, o mecanismos combinados de pago.

Los gobiernos de la década de 1990 y 2000 utilizaron la contratación pública para establecer una nueva gobernanza en área de la salud, basada en la construcción de los cuasimercados. Estas reformas han tenido problemas en su implementación (Ugalde y Homedes 2005b), principalmente por parte de los trabajadores del sector salud (Mesa-Lago 2005). Este modelo también presentó dificultades por la falta de un marco jurídico y regulación, que repercutió en corrupción y altos costos (Mesa-Lago 2005). Tres cuestiones explican que la implementación de estos cuasimercados no haya tenido los resultados esperados. La primera fue la atomización que promueven (Katz y Miranda 1994), que estos cuasimercados se implementaron para disminuir las deudas (Barba Solano 2012) y que no permiten un control real. La segunda de ellas es que la competencia no genera una articulación en red, acentuando la fragmentación de los sistemas de salud (OPS 2010). La tercera es que la competencia solo se da en espacios geográficos en donde existe una mayor cantidad de población que puede pagar. En las zonas extremas, abundan los prestadores únicos, cuando los hay. PNUD (2018) exhibe este resultado. En las regiones más apartadas y/o con menor densidad poblacional, el sector privado es casi inexistente. El cuasimercado sanitario no integró a los diferentes prestadores como teorizaron los impulsores del sistema intensivo del uso de contratos (Franco-Giraldo 2014).

En el caso colombiano, la contratación de servicios de salud existe, pero se regula de una forma extraña. Los entes aseguradores compran servicios a proveedores públicos y privados. Los centros asistenciales públicos se transformaron en empresas sociales estatales que celebran contratos privados a los que, eventualmente, podría aplicarse las potestades exorbitantes de la Administración (Lozada Pimiento 2006, Rivera Jiménez, Vargas Aldana y Moreno Casasbuenas 2017). El caso chileno están los servicios de salud y los establecimientos autogestionados en red u hospitales autogestionados, que se proveen de atenciones de salud utilizando la Ley de Compras Públicas (Flores Díaz 2020a). 
Un informe de Chile Transparente del año 2019 indica que la contratación pública en el sector salud es un aspecto muy oscuro, con muchas irregularidades. Respecto a las compras realizadas por el sector salud, el informe advierte que no existen mecanismos de corroboración de efectiva competencia en el mercado, lo que da paso a especulaciones con direccionamiento de bases o acuerdos previos a la presentación de ofertas. El estudio también muestra que la fiscalización es insuficiente y las sanciones inefectivas, lo que permite comportamientos discrecionales de las autoridades adjudicadoras y también genera un ambiente propicio para la corrupción. Chile Transparente señala que más de un 50\% de las compras del sector salud se realizan por trato directo, y en el caso de los servicios de salud y hospitales, sobre un $65 \%$ de las licitaciones tuvieron un solo oferente, lo que conlleva a sobreprecios y prácticas monopólicas. Además, el sector salud concentra los reclamos y las evaluaciones negativas del portal mercado público (Chile Transparente 2019: 95).

El CONTRATO PÚbliCO COMO MECANISMO DE ARTICULACiÓN DE LA RED ASISTENCIAL

El contrato público, como muchas de las instituciones del Derecho Administrativo, es una aplicación de la teoría general del Derecho, cuya especialidad está en que es celebrada por un poder público en el cumplimiento de sus fines (Muñoz Machado 2018). Lo que justifica la existencia de la categoría contrato público es que sirve al interés general (Ariño 2007, Meilán Gil 2018). Los elementos comunes a la amplia gama de contratos del sector público son tres: 1) la existencia de un sujeto que realiza un cometido público (o, como señala el derecho europeo, un poder adjudicador); 2) que utiliza fondos públicos; y 3) que sirve al interés general.

En consecuencia, repensar los contratos del sector público sanitario con prestadores privados lleva implícita la idea de proteger el interés general. Ello pasa, no para cuestiones de equilibrio presupuestario, sino porque el acceso a la asistencia sanitaria dependa de la necesidad de recibir las prestaciones de salud y no de la capacidad adquisitiva (Oliva Moreno, González López-Valcárcel, Trapero Bertrán, Hidalgo Vega y Del Llano Señarís 2018). En este sentido, el uso de contratos para articular redes asistenciales ha permitido un proceso de diálogo que incluye

[...] una rectificación de los problemas en el momento en que surgen; un intercambio de conocimientos y habilidades; riesgos compartido, pérdidas y ganancias; relaciones más estables y largas; 
y la construcción del sentido de responsabilidad (Vilaça Mendes 2013: 188).

La participación del sector privado es positiva y necesaria en la medida que complemente a la red pública. Contrariamente, concebir a ambos sectores como competidores genera el problema que presentaron las reformas de los años noventa en el National Health Service británico, que planteaban la libertad de elección y la competencia para mejorar la eficiencia, sin considerar que los establecimientos públicos no podían quebrar o ser cerrados, como supondría la teoría económica.

La diferencia radica en que el contrato es un mecanismo de incorporación a una determinada red, lo que permite a los prestadores públicos y privados compartir información y generar bases de datos sobre las necesidades de la población lo que facilita la planificación actual y futura de los servicios de salud (OPS 2010). Los casos de Brasil (Pereira Barboza 2017) y Costa Rica (El Mundo 2019) son un ejemplo de esta articulación con el sector privado en una red, y la evaluación del sistema es positiva.

Costa Rica es un caso paradigmático de contratación de servicios de salud. La Caja Costarricense de Seguro Social celebra contratos con prestadores privados, cuestión que le permitió ampliar la oferta de servicios profesionales (OCDE 2017). En la actualidad existen los compromisos de gestión en los que se provee servicios de diagnósticos y tratamientos de alta complejidad, entre otros (Sáenz, Acosta, Muiser y Bermúdez 2011). En los casos brasileńos y costarricense se utiliza el contrato público para articular redes asistenciales, en las cuales el privado reemplazará al sector público en aquellos lugares en que este no exista o no pueda desempeñar funciones (OPS 2010).

\section{LA APLICACIÓN PARADOJAL DE LA LEY DE COMPRAS EN EL CASO CHILENO: FONASA Y LOS ESTABLECIMIENTOS DE LOS SERVICIOS DE SALUD}

\section{LA NORMATIVA DE PARTICIPACIÓN DE LOS PRIVADOS EN LA PRESTACIÓN DE ACCIONES DE SALUD}

El artículo $19 \mathrm{~N}^{\circ} 9$ de la Constitución Política de la República establece la existencia de dos sistemas de salud, uno público que corresponde a Fonasa, y otro privado que está en manos de las Isapres. Tal como se señaló, menos de un $20 \%$ de la población está asegurada por las Isapres, mientras que cerca de un $80 \%$ es beneficiaria de Fonasa. Los afiliados a Isapres solo pueden acceder a establecimientos privados de salud, a menos que se trate 
de una situación de Ley de Urgencias, o un tratamiento de alguna patología incluida en las garantías explícitas de salud (GES), o si la Isapre celebró un convenio especial con el servicio de salud, cuestión que hacen las Isapres cerradas. En cualquier otro evento, no tendrían cobertura por parte de la aseguradora.

Mientras tanto, los beneficiarios de Fonasa son usuarios de los centros asistenciales dependientes del SNSS. Al respecto, el artículo 2 del Decreto con Fuerza de Ley $N^{\circ} 1 / 2005$ establece que el SNSS es un esquema de colaboración público-privado. En efecto, la citada disposición señala:

Artículo $2^{\circ}$.- Para los efectos del presente Libro, integran el sector salud todas las personas, naturales o jurídicas, de derecho público o privado, que realicen o contribuyan a la ejecución de las acciones mencionadas en el artículo $1^{\circ}$.

Las personas naturales o jurídicas, públicas y privadas que laboran en salud coordinadamente, dentro de los marcos fijados por el Ministerio de Salud para el cumplimiento de las normas y planes que este apruebe, constituyen el Sistema Nacional de Servicios de Salud, en adelante el Sistema.

Incluso, permite que los privados con fines de lucro sean parte de la red asistencial. Por su parte, el artículo 17 del mismo cuerpo legal establece que la red asistencial de cada servicio de salud está constituida por el conjunto de centros asistenciales públicos, municipales y privados que suscriban un convenio de adscripción. Desde el ańo 2006, estos convenios se rigen por la normativa de la Ley de Compras Públicas, de acuerdo a la interpretación que la Contraloría General de la República realizó en los dictámenes № 51.081 de 2006 y No 38.109 de 2007. Ellos ordenaron la aplicación de la Ley de Compras a los convenios regulados por el Decreto con Fuerza de Ley $\mathrm{N}^{\circ} 36 / 80$. Lo mismo hizo el dictamen $\mathrm{N}^{\circ} 59.990$ de 2008, respecto de los convenios contemplados en el artículo 24 de la Ley $\mathrm{N}^{\circ} 19.664$, que permite a los directores de los servicios de salud autorizar la contratación de especialistas en caso de necesidad. Además, la redacción de la Ley de Compras Públicas permite su aplicación supletoria a cualquier acuerdo de carácter oneroso (Camacho 2008), es decir, que implique la transferencia de fondos públicos a un privado a cambio de una contraprestación.

En relación con los convenios del Decreto con Fuerza de Ley $N^{\circ} 36 / 80$ en 2011, la Contraloría sostuvo en su dictamen $N^{\circ} 44.822$, que estos convenios implicaban un traspaso de funciones públicas, cambiando el carácter del convenio de una simple compra de suministros a un acuerdo de adscripción a la red de salud. Este criterio lo mantuvo en el dictamen 
$\mathrm{N}^{\circ} 11.781$, de 2018, que ordenó dejar sin efecto protocolo de objeción de conciencia, entre otras razones, porque las entidades que suscribieron un convenio del Decreto con Fuerza de Ley $\mathrm{N}^{\circ} 36 / 80$, desarrollan una función pública, por lo tanto, no podían adoptar una posición que les impidiera realizar las atenciones de salud a las que el Estado se encuentra obligado a brindar. Este criterio fue confirmado por el dictamen $\mathrm{N}^{\circ} 24.216$ del mismo año.

Sin embargo, en su sentencia de 18 de enero de 2019, el Tribunal Constitucional reduce estos acuerdos a simples compras de servicios, al sostener, en su considerando decimoctavo, que la teoría del servicio público no es compatible con el derecho chileno. Por lo tanto, no sería posible entender estos convenios como un traspaso de funciones. El redactor de la sentencia fue el ministro Iván Aróstica, que en 1994 publicó el trabajo "Transferencia de funciones estatales al sector privado en tres contratos administrativos: concesión de servicio público, externalización y sociedad" sosteniendo la tesis contraria a lo que concluyó en el fallo.

El mensaje presidencial 580-367, de 5 de enero de 2020, que contiene el proyecto de ley para reformar Fonasa y crear un plan de salud universal, contempla un artículo $2^{\circ}$ que deroga el Decreto con Fuerza de Ley $\mathrm{N}^{\circ}$ $36 / 80$. En este sentido, el proyecto confunde el convenio del Decreto con Fuerza de Ley $N^{\circ} 36 / 80$, que ha sido mal usado por los servicios de salud y los establecimientos autogestionados en red u hospitales autogestionados, con las facultades contenidas en el artículo 35, letra g) Decreto con Fuerza de Ley $\mathrm{N}^{\circ} 1 / 2005$, permite a sus directores

Celebrar contratos de compra de servicios de cualquier naturaleza, con personas naturales o jurídicas, para el desempeño de todo tipo de tareas o funciones, generales o específicas, aun cuando sean propias o habituales del Establecimiento.

El límite para estos contratos es el 20\% del presupuesto anual. Esta disposición, y el mal uso del Decreto con Fuerza de Ley $\mathrm{N}^{\circ} 36 / 80$, permitieron la proliferación de las sociedades médicas, sobre las que se volverá más adelante.

Esta discusión deja de manifiesto la necesidad de perfeccionar el sistema de contratación pública y los mecanismos de asociación del sector privado con la Administración del Estado, y una regulación específica de los contratos del sector salud, con adecuados mecanismos de ejecución y fiscalización. También evidencia la necesidad de articular de mejor manera las redes asistenciales y el rol de la autoridad sanitaria. 
El caso chileno es paradojal pues usa contratos para comprar prestaciones a privados y para generar redes asistenciales. Las diferencias están en las bases de licitación y, sobre todo, en quién realiza la contratación.

En la legislación chilena, los convenios del sector salud agrupan una serie de acuerdos innominados que, en el ámbito público, se tratan de compromisos de gestión. Respecto de relaciones entre el sector público y proveedores privados, se refieren a contratos innominados con naturaleza y finalidad diferente. Por un lado, tienen por objeto la vinculación de centros privados a la red asistencial pública, también para encomienda de labores, o de sustitución de la Administración en determinadas prestaciones sanitarias o para la venta de servicios, entre otras posibilidades.

Hasta la década de 2000 no existían normas legales que regularan la contratación externa de servicios en el sector salud. Inicialmente, los directores de los servicios de salud tenían facultades de compra de bienes y servicios. Solo existía el artículo 20, letra i) del Decreto Ley N ${ }^{\circ} 2.763 / 79$ (actual artículo 23, letra i) del Decreto con Fuerza de Ley $\mathrm{N}^{\circ} 1 / 2005$ ), que faculta a los directores de los servicios de salud para pagar a entes privados por labores en que fuesen sustituidos por estos. Esta disposición remite al artículo $9^{\circ}$ transitorio del Decreto Ley $\mathrm{N}^{\circ} 2.763 / 79$, que facultad al poder ejecutivo a dictar un decreto con fuerza de ley que regule los convenios de adscripción al SNSS. Este fue el Decreto con Fuerza de Ley $N^{\circ} 36 / 80$.

El propósito inicial de este decreto fue construir un sector privado utilizando la infraestructura del sector público (Moraga Cortés, Bahia Coelho y Prada Sanabria 2018), que reemplazara al sistema público (Raczynski 1983). Esto no ocurrió del modo planificado por la crisis económica de inicios de la década de 1980. En la práctica, estos convenios se utilizaron para diferentes materias en las que estuviera involucrado algún servicio de salud.

Las primeras regulaciones legales de las relaciones contractuales en el sector salud se establecen en las leyes de presupuestos de la década de 1990, que facultan al Ministerio de Salud y a Fonasa para celebrar compromisos de gestión con los servicios de salud. Recién con las leyes № 19.650 de 14 de noviembre de 1999 , y № 19.664 de 28 de enero de 2000, se incorporan los convenios de forma permanente en la legislación chilena. La ley $\mathrm{N}^{\circ}$ 19.650 se denominó Ley de Compra Pública (Instituto de Administración de Salud 2013), pues redefinió la función financiera de Fonasa al modificar el artículo 27 letra b), del Decreto Ley N 2763 (actual artículo 50 letra 
b), del Decreto con Fuerza de Ley $\left.\mathrm{N}^{\circ} 1 / 2005\right)$. El enunciado original de la disposición en comento señalaba que Fonasa financiaría las acciones de salud por aportes o pagos directos. La Ley $\mathrm{N}^{\circ} 19.650$ incorporó el financiamiento por medio de convenios y se añadió la posibilidad que centros que no pertenecieran al SNSS celebraran convenios con Fonasa para ser parte de la modalidad de atención institucional (MAI).

Es necesario recordar que la Ley $\mathrm{N}^{\circ} 18.469$ estableció que Fonasa brindaría cobertura de salud en dos modalidades: la institucional o MAI, realizada por establecimientos públicos, y la modalidad de libre elección (MLE), efectuada por prestadores privados que suscribieran un contrato con el Fonasa. La modificación realizada por la Ley $\mathrm{N}^{\circ} 19.650$ permitió que, por medio de estos convenios, establecimientos no pertenecientes al SNSS, como los hospitales universitarios, institucionales (de las Fuerzas Armadas y la Policía) y determinados centros privados, entre otros, fuesen parte de la MAI.

El propósito de esta facultad era reducir las listas de esperas y garantizar las prestaciones y derechos establecidos en la reforma AUGE/GES. Tanto los directores de los servicios de salud y de los establecimientos autogestionados en red $\mathrm{u}$ hospitales autogestionados estaban facultados para comprar las atenciones necesarias a prestadores privados y de este modo reducir las listas de espera (Biblioteca del Congreso Nacional 2018c). De este modo, se avanzó en la consolidación de un mercado de prestaciones sanitarias. Había un paquete básico de prestaciones sanitarias garantizadas por el Estado que el sector público no tenía la capacidad de otorgar, lo que forzó a los diferentes actores del SNSS a comprarlas en el sector privado (Segovia 2017). En 2010, la Subsecretaría de Redes Asistenciales emitió la Resolución Exenta No 368 de 12 de febrero, cuyo párrafo IV, No 6 establece que para las prestaciones GES y otras destinadas a reducir las listas espera será necesario establecer un convenio especial con los profesionales sanitarios. Como se verá más adelante, no se estableció ningún procedimiento para su celebración ni existe evidencia de que se cumplen los controles internos que esta resolución indica.

El caso paradigmático es el de las compras de evaluaciones médicas y de diálisis, en las que el sistema público solo tiene el 11\% de los centros y el sector público solo el 10\% de los pacientes que requieren diálisis (Cámara de Diputados 2017). Estas prestaciones son los que constituyen la mayor cantidad de compras realizadas por los entes públicos a proveedores privados. 
La subsunción de las relaciones contractuales a compras públicas también repercutió en los convenios del Decreto con Fuerza de Ley $\mathrm{N}^{\circ}$ $36 / 80$, pues las diferentes leyes de presupuestos los catalogaron en el subtítulo de transferencias corrientes hasta que en el año 2005 se movieron al subtítulo 22 de gastos en bienes y servicios de consumo. En el caso del Ministerio de Salud, este subtítulo otorga recursos para realizar una serie de contrataciones con entes públicos y privados, con única limitación que este gasto no sea para otorgar remuneraciones por servicios personales.

La incorporación del Decreto con Fuerza de Ley N 36/80 en el subtítulo de transferencias corrientes tenía un sustento legal. El mencionado artículo 20, letra i) del Decreto Ley $\mathrm{N}^{\circ} 2.763 / 79$ (actual artículo 23, letra i) del Decreto con Fuerza de Ley $\left.N^{\circ} 1 / 2005\right)$ se refiere a la retribución que recibiría el proveedor privado como traspaso de fondos presupuestarios. En el manual elaborado por la Dirección de Presupuestos del ańo 2004 se indica que este concepto se refiere, entre otros asuntos, a programas especiales y gastos inherentes o asociados a la realización de estos. En este sentido, el mismo manual catalogó las transferencias presupuestarias a prestadores privados como subvenciones a instituciones que prestan servicios de asistencia médica (Dirección de Presupuestos 2004). Un concepto similar entrega el clasificador de gastos de ingresos y gastos del Decreto Supremo No 854 de 29 de septiembre de 2004, del Ministerio de Hacienda, que determina las clasificaciones presupuestarias.

En la Ley de Presupuestos del año 2005, los convenios del Decreto con Fuerza de Ley $N^{\circ} 36 / 80$ se incorporaron en el subtítulo 22 de gastos en bienes y servicios de consumo. Este ítem se refiere a la adquisición de bienes de consumo y servicios no personales necesarios para el cumplimiento de las funciones y actividades de los organismos del sector público (Dirección de Presupuestos 2005). Cuando el clasificador presupuestado del aludido Decreto Supremo No 854 de 2004 utiliza la expresión de servicios no personales, se refiere a que por ese concepto no podrán contratarse labores propias del personal de la administración individual. Sin embargo, la disposición es ambigua y, desde 2005 en adelante, las leyes de presupuestos dejan las compras de servicios de prestaciones de salud en el subtítulo 22, en el entendido que se contratan con personas jurídicas lo que impediría imputar ese gasto al subtítulo 21 de gastos de personal.

Este proceso coincidió con la promulgación y entrada en vigor de la Ley de Compras Públicas de 2003. De este modo, ocurrió que la externalización de prestaciones sanitarias al ser consideradas como una compra de servicios, se le aplicó la Ley de Compras Públicas. Pero esta consecuencia no fue prevista por los diseñadores de la reforma AUGE/GES. La cuestión se 
produjo por la redacción de la Ley de Compras Públicas y la intervención de la Contraloría.

El artículo 1 de la Ley de Compras Públicas establece su ámbito de aplicación a los contratos celebrados por la Administración del Estado, a título oneroso para el suministro "de los servicios que se requieran para el desarrollo de sus funciones". Por su parte, el artículo 3 establece taxativamente las excepciones al ámbito de la aplicación de esta ley, entre las cuales no se incorporó ninguna relativa a los servicios de salud. El artículo 20 de este cuerpo legal establece una obligación para los órganos del sector público -con excepción de las empresas públicas- de suministrar al portal de ChileCompra la información básica sobre contratación de bienes, servicios y obras y aquella que determine el reglamento. El artículo 57 del reglamento establece que esta información se refiere a el llamado a contratación, las bases, las respuestas a las preguntas efectuadas por los proveedores, la recepción y el cuadro de las ofertas, la resolución o acto que resuelva la adjudicación y los datos precisos del contrato, y, por último, el texto del contrato de suministros y servicios definitivo, si lo hubiere. En consecuencia, las contrataciones de bienes y servicios debían publicarse en el portal de ChileCompra.

Sin embargo, la discusión sobre la aplicación completa de la Ley de Compras a los convenios celebrados por el sector público sanitario con proveedores privados se dio en el año 2006, con motivo de la toma de razón de la resolución $\mathrm{N}^{\circ} 182$, de ese año, del Servicio de Salud Metropolitano Occidente, que modificó el precio que se debería pagar a unas sociedades médicas por dar atención profesional a cuatro pacientes de un hospital público. La licitación se hizo para atender a cuatro pacientes y luego de adjudicada se modificó para que los pacientes fuesen 14, modificando las bases originales de licitación ya adjudicada. Esta resolución fue representada por la Contraloría a través de su dictamen $\mathrm{N}^{\circ} 46.126$ de ese año. Simultáneamente, el Subsecretario de Redes Asistenciales realizó una consulta a la CGR por la vigencia del Decreto con Fuerza de Ley $N^{\circ} 36 / 80$, respondida por el citado dictamen N N$^{\circ} 51.081$ de 2006.

\section{Servicios de Salud y Fonasa: Los entes Que compran PRESTACIONES}

El sector salud es el principal usuario de la Ley de Compras Públicas. De acuerdo al portal ChileCompra (s.f.), este sector lidera el monto gastado con $\$ 3.160 .418 .258$, seguido por el sector gobierno central y universidades, con $\$ 2.052 .484 .412 .956$. Es decir, el gasto en salud equivale a casi un $154 \%$ del gasto realizado por el gobierno central y las universidades. Los 
servicios comprados por el sector salud van desde la construcción y el aseo hasta la prestación de atenciones de salud, como la compra de servicios de diálisis o las cirugías de cataratas.

El uso de compras públicas en la provisión de servicios se justifica para reducir las brechas de profesionales y de infraestructura existentes en el sector público. Por regla general, las compras de servicios se refieren a atenciones de profesionales de la salud que no están disponibles en el sector público y en camas para episodios críticos. Las brechas se dan en materia de recursos humanos y físicos.

El subsistema público concentra la infraestructura y los beneficiarios. Sin embargo, el sector privado supera con creces al público en la cantidad de profesionales médicos que puede ofrecer. El informe de Brechas de la salud del año 2016, elaborado por la Subsecretaría de Redes Asistenciales (2017) establece que el subsistema público tiene solo un $45 \%$ de los médicos generales y especialistas, pero si esto se mide en horas aparece que un $62 \%$ de las horas médicas se concentran en el sector privado (Clínicas de Chile A.G. 2016). La regulación legal de las profesiones de la salud, contenida en las leyes $\mathrm{N}^{\circ} 19.664$ y $\mathrm{N}^{\circ} 15.076$, permiten la contratación de profesionales por 11, 22, 33 y 44 horas. La cuestión es compleja pues en los hospitales públicos están los médicos funcionarios contratados por horas que después venden servicios como sociedades médicas a su mismo empleador.

El concepto de sociedades médicas nace en la regulación tributaria. Se trata de personas jurídicas organizadas de diferentes formas que inician actividades en el SII con el Código 862031, correspondiente al giro o actividad económica servicios de médicos prestados de forma independiente, y obtienen su registro único tributario (RUT), con el cual venden sus servicios profesionales y además pueden vender al Estado. Mediante la solicitud por Ley de Transparencia AE006W50017805, el SII indica que entre 2002 y 2019 , se inscribieron 5.007 personas jurídicas con este giro. De acuerdo a la información solicitada vía Ley de Transparencia AE011T0002050, ChileCompra indica que en 2019 existen 279 sociedades médicas inscritas como proveedores de la plataforma Mercado Público, es decir, que pueden celebrar contratos de la Ley de Compras Públicas. En ese mismo año, se gastaron cerca de $\$ 550$ mil millones de pesos de los cuales $\$ 300$ mil millones fueron a sociedades médicas (Veloso 2020).

Si uno de los objetivos del uso de contratos públicos era pasar de mecanismos de pago retrospectivos a pagos prospectivos, las sociedades médicas son la constatación de que ese objetivo no se cumplió. Las licitaciones a sociedades médicas se hacen en la mayoría de los casos por 
trato directo, y las pocas veces que se licitan, solo hay un oferente. Por lo tanto, el prestador privado puede subir los precios y el sector público está obligado a pagar para cumplir con la garantía de oportunidad.

La atomización del sistema público de salud generó este cuasimercado de sociedades médicas que utilizan la infraestructura pública para cobrar sobreprecios al Estado. Este punto refleja lo que indican los expertos en economía de la salud, que en este campo no se cumple ninguno de los requisitos para el funcionamiento óptimo de un mercado de competencia perfecta (Oliva Moreno et al. 2018).

En un estudio de 2016, la Dirección de Presupuestos explica que las compras al sector privado se dividen en dos grupos. Las compras a las sociedades médicas las denomina eufemísticamente compras intrasistema, pues este sector privado está compuesto por funcionarios de planta o contrata de los diferentes entes del SNSS que venden sus servicios a los mismos establecimientos que los contratan (Ahumada, Lagos y Sugg 2016). Las compras a las sociedades pasaron de $\$ 92.004$ millones en 2008 a \$213.829 millones en 2015 (Ahumada, Lagos y Sugg 2016: 19). Los sobreprecios pagados a las sociedades médicas son responsables de cerca un $30 \%$ de la deuda hospitalaria. La solución gubernamental fue regular estos convenios en el subtítulo 22 letra e), de la partida presupuestaria del Ministerio de Salud, en la Ley $\mathrm{N}^{\circ} 21.053$, de presupuestos del sector público de 2018. La regulación indica:

Los Servicios de Salud, establecimientos dependientes, Establecimientos de Autogestión de Red (EARs) y establecimientos creados por los D.F.L. $\mathrm{N}^{\circ}$ s 29,30 y 31 del Ministerio de Salud, año 2001, deberán aplicar para la contratación de servicios con sociedades de profesionales de servicios de medicina u otra de similar naturaleza, los procedimientos establecidos en la Ley N 19.886 , de Bases sobre Contratos Administrativos de Suministros y Prestación de Servicios; debiendo contratar preferentemente a profesionales con la calidad de titular o contrata en el Sistema Público de Salud.

El origen legal de estas compras está en dos disposiciones. La primera es el artículo 4, letra c), de la Ley $\mathrm{N}^{\circ} 19.966$, que estable la garantía de oportunidad. La segunda es el artículo 36, letra g), del Decreto con Fuerza de Ley $\mathrm{N}^{\circ} 1 / 2005$, que otorga las más amplias facultades a los directores de los establecimientos autogestionados en red u hospitales autogestionados celebrar contratos de compra de servicios para el desempeño de funciones propias del establecimiento. 
Cuando se instaló el cuasimercado, los funcionarios intentaron competir con los prestadores privados del extrasistema público. Para ello, se organizaron como una persona jurídica de derecho privado para ofrecer los mismos servicios que el sector privado, utilizando la infraestructura pública. De este modo, los recursos quedaban en manos de los mismos funcionarios, pero no del establecimiento. La atomización de las unidades de salud con capacidad de contratar produce un aumento de la deuda hospitalaria. A esto hay que ańadir la poca capacidad de fiscalización.

El cuasimercado sanitario chileno permite una constante merma en los presupuestos públicos pues su carácter contingente, de atender la garantía de oportunidad induce a pagar por servicio (pago retrospectivo) y no a planificar mecanismos prospectivos que induzcan el ahorro. Por lo tanto, la adopción del cuasimercado produce mayores costos, no cumpliendo la promesa de un ahorro. La diferencia está en que el déficit lo experimentará el establecimiento de salud.

El informe N 500 de 2018, de la Contraloría General de la República consolidó las auditorías realizadas al SNSS. En él se da cuenta de diferentes anomalías en la contratación de sociedades médicas. En 9 de los 27 de los hospitales investigados se pagó un arancel mayor a contemplado por Fonasa. En la mayoría de los casos no existe un contrato formal entre el establecimiento y la sociedad médica y en otros se abusa del trato directo. Además, estas no se registran en la contabilidad para no rendir cuenta de los gastos.

En 2019, el secretario general del Colegio Médico defendió la existencia de las sociedades médicas, pues sirven para absorber la demanda de los pacientes del sistema público (Ferrer 2019). Lo cierto es que ningún gobierno ha querido ponerle fin a este asunto. El proyecto de ley que reforma Fonasa pretende eliminar los convenios del Decreto con Fuerza de Ley $\mathrm{N}^{\circ}$ $36 / 80$, pero nada dice de la facultad de los directores de los establecimientos autogestionados en red u hospitales autogestionados de comprar servicios. En la respuesta a la solicitud AE011T0002146, ChileCompra indica que entre 2008 y 2019 se celebraron solo ocho convenios (uno en 2008, uno en 2010, uno en 2015, tres en 2017 y dos en 2019). De acuerdo a la regulación legal de estos convenios, estos tienen una duración máxima de un año. En consecuencia, la derogación del Decreto con Fuerza de Ley $\mathrm{N}^{\circ} 36 / 80$ no ataca el problema de fondo. Más bien responde a intereses políticos para que el Ministerio de Salud no pueda imponer directrices a los privados que celebran convenios con entes del SNSS. 
Otro aspecto a considerar es la operatividad del SNSS. Un informe de la Comisión Nacional de Productividad del año 2020 destinado a explicar el crecimiento de las listas de esperas, detectó que los pabellones hospitalarios no se usan en un $100 \%$ de su capacidad, sino que están una buena parte del tiempo sin actividad. El exceso de demanda y el crecimiento de listas de esperas puede explicarse en una parte porque no se usan los recursos de forma adecuada. Además, el Decreto con Fuerza de Ley $N^{\circ} 1 / 2005$ permite que los médicos usen estas instalaciones para sus actividades privadas. El incentivo es perverso.

Las otras transferencias al sector privado corresponden a las compras extrasistema, relativas a las prestaciones que se realizan en establecimientos fuera de la red pública, ya sea por derivación, en caso de la garantía de oportunidad, o por ley de urgencias. Aunque el volumen de estas compras es más alto, desde 2008 hay una tendencia a la baja en su participación. La explicación está en la implementación de la Unidad de Gestión Centralizada de Camas (UGCC), que estableció un mecanismo monitoreo de camas en el Sistema público para priorizar la derivación de los usuarios de Fonasa a la misma red pública, luego a los hospitales institucionales y, finalmente, a establecimientos privados, previa licitación (Ministerio de Salud 2018).

Las experiencias de Fonasa al establecer alianzas con prestadores privados para la atención de usuarios del servicio público son positivas. En primer lugar, permiten el acceso a servicios privados lo que es valorado por la población. En efecto, el informe Desiguales del PNUD indica que los servicios de salud son el tercer lugar donde se producen más malos tratos (2018), y los usuarios evalúan mejor a los prestadores privados que a los entes públicos, e incluso, se percibe que los médicos del sector privado atienden se toman más tiempo con los pacientes y explican mejor los tratamientos prescritos (2018).

Existen alianzas público-privadas en salud que gozan de buena aprobación y tienen buenos resultados. Se trata de las licitaciones preparadas por la Unidad de Gestión Centralizada de Camas en conjunto con Fonasa.

Está la licitación aprobada por la resolución $\mathrm{N}^{\circ} 1$ de 2015, de Fonasa, que fue la primera en su especie y estableció un pago por atenciones basado en los grupos relacionados de diagnóstico (GRD) lo que induce a optimizar el uso de recursos económicos. Esta licitación tuvo un buen nivel de participación. La resolución $N^{\circ} 77$ de 2017 de Fonasa fue la siguiente licitación. En ambas se estructuró la licitación para que las personas atendidas por Ley de Urgencias permanecieran en los recintos privados hasta su alta médica, y no hasta su estabilización, lo que obligaba 
al sector público a rescatar al paciente y si esto no ocurría, el paciente debía desembolsar los costos derivados su hospitalización en los centros privados (Ministerio de Salud 2018). En 2018, hubo un retroceso con la nueva licitación que volvió al criterio del rescate, motivado por el cambio de autoridad sanitaria.

Los convenios de la Ley de Urgencias están regulados en el artículo 50, letra b) del Decreto con Fuerza de Ley $N^{\circ} 1 / 2005$, son catalogados por expertos como la tercera modalidad de Fonasa, después de la MAI y la MLE (Sepúlveda Serrano 2017). En las leyes de presupuesto del sector público se les catalogó como convenios de provisión de prestaciones médicas, y en las glosas presupuestarias respectivas indica que para su celebración se aplicarán las disposiciones de la Ley de Compras Públicas. Por eso las licitaciones de 2015 y 2017 fueron un avance en la materia, al ser las primeras.

La dificultad de estas licitaciones es su periodo acotado, 18 meses, y la falta continuidad de las autoridades sanitarias. En efecto, en 2018 hubo un cambio de gobierno, y la licitación de ese año, aprobada por la resolución $\mathrm{N}^{\circ} 46$ de 2018, de Fonasa, en la que se aplicaron los estudios y opiniones del ministro de salud de la época (considerando $8^{\circ}$ ). Esto indujo algunos cambios, toda vez que ese ministro de Salud hasta antes de asumir esa cartera, había sido el gerente de uno los participantes en las licitaciones.

El proyecto que modifica propone potenciar este rol de Fonasa como comprador de prestaciones de salud. La experiencia indica que es una buena medida, toda vez que una autoridad centralizada para comprar y articular una red ha tenido buenos resultados. También reivindica el rol del contrato público como mecanismo de modernización. Mientras el sector público aún no puede pasar de pagos retrospectivos al sector público, como son los programas de prestaciones institucionales -basado en la historia presupuestaria y no asociado a la actividad hospitalaria- y los programas de prestaciones valoradas - pago por prestaciones realizadas- ya puede aplicar el pago por grupos relacionados de diagnóstico en sus convenios con el sector privado. En efecto, el gasto operacional ejecutado por los servicios de salud pasó de un 11\% del presupuesto en 2008 a un 21,9\% en 2017.

\section{CONCLUSIONES Y PROPUESTAS}

El debate entre los partidarios del sistema unitario y los defensores de los sistemas pluralistas repercutió en la concepción acerca de las relaciones contractuales entre prestadores de servicios y entes financieros. En los sistemas unificados, los contratos se utilizaron para establecer alianzas 
de cooperación y articular redes asistenciales. En los sistemas pluralistas, las relaciones contractuales fueron compras de servicios, con los que la autoridad política intentó crear condiciones de mercado en la gestión sanitaria.

Los problemas en el uso de los contratos está en las autoridades que los elaboran y el propósito para el cual los usan. Si son usados para articular un cuasimercado, su éxito será discreto, como se indicó en los casos señalados. Esto implica pasar de la concepción del contrato público como una simple compra y articularlo como una alianza de largo aliento con el sector privado.

Los contratos realizados por organismos centralizados que compran un mayor volumen de prestaciones y manejan mejor información del sistema público arrojan mejores resultados. Por lo tanto, mantener la atomización del sistema de salud solo induce a un mayor gasto y resultados ineficientes.

Esto es lo que sucede en Fonasa con las licitaciones por Ley de Urgencias. Sin embargo, ello no ocurre en las compras de los servicios de salud ni en los establecimientos autogestionados en red $\mathrm{u}$ hospitales autogestionados en los que las compras públicas se han utilizado para otros fines, como indica el informe $N^{\circ} 500$ de 2018, de la Contraloría General de la República, en que se constata que muchas de estas compras han implicado una defraudación al fisco. Para esto se requiere una regulación de los contratos del sector que nos haga pensar en alianzas y no en compras, una diferencia del papel que asume el privado, siendo un delegado de la Administración en la ejecución de tareas públicas y no solo un vendedor de servicios, como ocurre en la actualidad.

El primer paso está en perfeccionar el Decreto con Fuerza de Ley $\mathrm{N}^{\circ}$ 36/80 y eliminar, o limitar al máximo, las facultades de compra que tienen los directores de los establecimientos autogestionados en red $\mathrm{u}$ hospitales autogestionados. El segundo es dejar de lado, por un momento, la discusión en torno a los seguros de salud, y centrarnos en la reforma a los prestadores. Los contratos del sector público con privados pueden cumplir esa tarea si se realizan de buena forma. Respecto del SNSS, se requiere de un esfuerzo titánico.

Finalmente, hay que avanzar hacia una contratación pública sanitaria que incorpore los aspectos claves del sector, y por qué no, que se emprenda una modificación sistemática, y en serio, de la actividad contractual del Estado, que incorpore un buen sistema de concesiones de servicios públicos. Esto puede ser una oportunidad que también nos invite a pensar regulaciones a 
los servicios públicos sociales y a estructurar una red de salud sin criterios de mercado basados en la competencia, sino que con criterios de eficiencia orientados hacia el interés general de la población. 


\section{REFERENCIAS}

Adhanom Ghebreyesus, T. (2017). La salud es un derecho humano fundamental. Disponible en https://www.who.int/mediacentre/news/ statements/fundamental-human-right/es/ [29-02-2020].

Ahumada, B., Lagos, M. y Sugg, D. (2016). Sobregasto Operacionaly Deuda del Sistema Nacional de Servicios de Salud. Disponible en https://www. dipres.gob.cl/598/articles-154339_doc_pdf.pdf [29-02-2020].

Albuquerque, M., Morais, H. y Lima, L. (2015). Contratualização em saúde: arena de disputa entre interesses públicos e privados. Ciência \& Saúde Coletiva, 20 (6), 1825-1834.

Alonso-Olea, B. y Medina, S. (2016). Derecho de los servicios públicos sociales (Cuarta edición). Navarra: Aranzadi.

Ariño, G. (2007). El enigma del contrato administrativo. Revista de Administración Pública, 172, 79-102.

Banco Mundial (1987). El financiamiento de los servicios de salud en los países en desarrollo. Una agenda para la reforma. Bulletin of the Pan American Health Organization, 103 (6), 695-709.

. (1993). Informe sobre el desarrollo mundial 1993: Invertir en salud. Washington: Banco Internacional de Reconstrucción y Fomento, Banco Mundial.

Barba Solano, C. (2012). Las reformas de los sistemas de salud en América Latina: los casos de las reformas de tempranas, intermedias y de tercera generación en México y Chile. En Fidel, C. y Valencia Lomelí, E. (Eds.), (Des)Encuentros entre reformas sociales, salud, pobreza y desigualdad en América Latina. Buenos Aires: Clacso.

. (2018). Liberalismo y universalismo en tensión. 25 años de reformas sociales en regímenes de bienestar de América Latina. En Midaglia, C., Ordoñez, G. y Valencia, E. (Eds.), Políticas sociales en América Latina en los inicios del siglo XXI. Buenos Aires: Clacso.

Barra, N. y Celis, G. (2015). Contratación Administrativa bajo la Ley de Compras (4a actualizada ed.). Santiago, Chile: Thomson Reuters. 
Báscolo, E., Houghton, N.y del Riego, A. (2018). Lógicas de transformación de los sistemas de salud en América Latina y resultados en acceso y cobertura de salud. Revista Panamericana de Salud Pública, 42 (126 e), $1-9$.

Becerril Montekio, V., Medina, G. y Aquino, R. (2011). El sistema de salud de Brasil. Revista Salud Pública de México, 53 (2 S), 120-131.

Becerril-Montekio, V., Reyes, J. y Annick, M. (2011). Sistema de salud de Chile. Salud Pública de México, 53 (2 S), 132-142.

Benatar, S., Sanders, D. y Gill, S. (2018). The global politics of healthcare reform. En McInnes, C., Kelley, L. y Youde, J. (Eds.), The Oxford handbook of global health politics. Oxford: Oxford University Press.

Benavides, J. L. (2016). Tendencias generales de la contratación pública en América Latina. En Benavides, J. L. y. Moreno Cruz, P. (Eds.), La contratación pública en América Latina. Bogotá: Universidad Externado de Colombia.

Benavides, J. L. y Moreno Cruz, P. (2016). La contratación pública en América Latina y la comparación jurídica. En Benavides, J. L. y. Moreno Cruz, P. (Eds.), La contratación pública en América Latina. Bogotá: Universidad Externado de Colombia.

Camacho, G. (2008). Los contratos administrativos, en especial el contrato de suministro. En Pantoja Bauzá, R. (Ed.), Derecho Administrativo: 120 años de cátedra. Santiago: Editorial Jurídica de Chile.

\section{. (2010). La actividad sustancial de la Administración del} Estado. Santiago: Thomson Reuters.

Cantero Martínez, J. (2018). Mercado interno sanitario y formas de gestión de los servicios ¿una vuelta hacia lo público? DS: Derecho y Salud, 28 (1 extra), 239-261.

Carnota Lauzán, O. (2017). El crecimiento de los costos en salud visto desde la ineficiencia. Revista Cubana de Salud Pública, 43 (4), 584-605.

Carvajal, Y. (2012). ¿Cuánto mide el sector privado de salud en Chile? Revista Chilena de Salud Pública, 16 (2), 170-171. 
Castro Jaramillo, H. (2014). Introducción. En Asociación Colombiana de Empresas de Medicina Integral (Ed.), Modelos de contratación en servicios de salud. Bogotá: Universidad Jorge Tadeo Lozano.

ChileCompra (s. f.). ¿Cuánto ha gastado el Estado? Disponible en http:// datosabiertos.chilecompra.cl [29-02-2020].

Chile Transparente y Observatorio del Gasto Fiscal en Chile (2019). Transparencia y competencia en las compras públicas chilenas. Disponible en http://www.chiletransparente.cl/wp-content/files_ $\mathrm{mf} / 1563468048$ CompiladodeComprasPublicas12MAR19.pdf $\quad$ [0106-2020].

Clínicas de Chile A.G. (2016). Dimensionamiento del Sector de Salud Privado en Chile Actualización a cifras año 2016. Disponible en http://www.clinicasdechile.cl/wp-content/uploads/2017/12/ DimensionamientoSaludCifras2016.pdf [01-06-2020].

Comes, Y. (s. f.). El concepto de derecho a la salud desde la perspectiva liberal y neoliberal: de negación a restricción del derecho. Disponible en https://www.siicsalud.com/acise_viaje/ensiicas-profundo. php?id=138278 [29-02-2020].

Cortez, N. (2015). Globalization. En Cohen, I. G., Hoffman, A. K. y Sage, W. (Eds.), The Oxford handbook of U.S. health law. Oxford: Oxford University Press.

Dirección de Presupuestos. (2004). Instrucciones para ejecución de la Ley de Presupuestos del Sector Público: Año 2004. Disponible en https://www. dipres.gob.cl/598/articles-37463_doc_pdf.pdf [29-02-2020].

(2005). Instrucciones para ejecución de la Ley de Presupuestos del Sector Público: Año 2005. Disponible en https://www. dipres.gob.cl/598/articles-37459_doc_pdf.pdf [29-02-2020].

Domínguez Martín, M. (2007). Formas de gestión de la sanidad pública en España. Madrid: La Ley.

Domínguez Martín, M. (2019). Los contratos de prestación de servicios a las personas. Repensando las formas de gestión de los servicios sanitarios públicos tras las directivas de contratos de 2014 y la Ley 9/2017 de contratos del sector público. Revista General de Derecho Administrativo, $50,1-2$. 
Domínguez Martín, M. y Peinado Chinchilla, J. A. (2018). La acción concertada en la gestión de servicios sanitarios en la Ley 9/2017 de contratos del sector público. DS: Derecho y Salud, 29 (Extra 1), 186193.

El Dinero. (2018). Sector Salud: ¿una década perdida? El Dinero, 25 de octubre. Disponible en https://www.dinero.com [29-02-2020].

El Mundo (2019). Costa Rica entre los seis países del mundo con mejor asistencia en salud. El Mundo, 28 de enero. Disponible en https:// www.elmundo.cr [29-02-2020].

Erazo, A. (2015). Un enfoque sistémico para comprender y mejorar los sistemas de salud. Revista Panamericana de Salud Pública, 38 (3), 248253.

Escoval, A., Ribeiro, R. y Matos, T. (2010). A contratualização em Cuidados de Saúde Primários: o contexto internacional. Revista Portuguesa de Saúde Pública, 9, 41-57. Recuperado de https://run.unl. pt/bitstream/10362/4464/1/T-10\%20ESCOVAL\%20p-41.pdf

Estefanía, J. (2016). Democracia y ciudadanía. En Martínez Lillo, P. y Estefanía, J. (Eds.), América Latina: Un nuevo contrato social. Madrid: Marcial Pons.

Ferrer, C. (2019). Pugna entre delantales blancos: Colegio Médico y Minsal se enfrentan por "crisis sanitaria» en hospitales públicos. Emol. com, 18 octubre. Disponible en https://www.emol.com/noticias/ Nacional/2019/10/18/964733/Crisis-sanitaria-falta-insumosManalich.html [29-02-2020].

Flores Díaz, S. (2020a). Contratación pública como mecanismo de gestión sanitaria indirecta: El caso de la compra de servicios médicos en el sistema chileno. En Valverde, G., Paredes, B., Miranda, M., Gallo, W., Zegarra, D. y Cairampoma, A. (Eds.), Nuevas tendencias e innovaciones del derecho administrativo. Memorias del II Congreso Latinoamericano Estudiantil de Derecho Administrativo. Belo Horizonte: Forum.

. (2020b). La "nacionalización" de la sanidad española y la salud chilena. El Mostrador, 23 de marzo. Disponible en https:// www.elmostrador.cl/noticias/opinion/columnas/2020/03/23/lanacionalizacion-de-la-sanidad-espanola-y-la-salud-chilena/ [01-062020]. 
Fondo Nacional de Salud (Fonasa). (s. f.). Base de datos, informes y documentos. Disponible en https://www.fonasa.cl/sites/fonasa/ documentos [01-06-2020].

Franco-Giraldo, A. (2014). Sistemas de salud en condiciones de mercado: las reformas del último cuarto de siglo. Revista Facultad Nacional de Salud Pública, 32 (1), 95-107.

García Pérez, F. (2018). La nueva contratación pública sanitaria y su control. Presupuesto y Gasto Público, 93, 117-127.

González López-Valcárcel, B. (2006). Políticas contractuales en atención especializada. En Repullo, J. y Ińesta, A. (Eds.), Sistemas y servicios sanitarios (pp. 289-333). Madrid: Ediciones Díaz de Santos.

(2019). Nuevos y viejos "modelos" para el Sistema Nacional de Salud. Disponible en https://nadaesgratis.es/beatrizgonzalez-lopez-valcarcel/nuevos-y-viejos-modelos-para-el-sistemanacional-de-salud [29-02-2020].

Instituto de Administración de Salud (2013). Informe Final Evaluación del Gasto Institucional del Fondo Nacional de Salud (FONASA). Disponible en https:/www.dipres.gob.cl/597/articles-141196_informe_final.pdf [01-06-2020].

Katz, J. y Miranda, E. (1994). Mercados de salud: morfología, comportamiento y regulación. Revista de la CEPAL, 54, 7-25.

Labaure Aliseris, C. (2000). Tercerización en la reforma del Estado. Revista de la Facultad de Derecho, 18, 157-164.

Laurell, A. C. (2012). Sistemas universales de salud: Retos y desafios. Disponible en https:/www.paho.org/ecu/index.php?option=com_ docman \&amp; view=download \&amp; category_slug=documentosnoticias-2012\&amp;alias=403-sistemas-universales-de-salud-retos-ydesafios\&amp;Itemid=599 [01-06-2020].

. (2016). Las reformas de salud en América Latina: Procesos y resultados. Cuadernos de Relaciones Laborales, 34 (2), 293314. 
Laurell, A. C. y Herrera, J. (2010). La segunda reforma de salud. Aseguramiento y compra-venta de servicios. Salud Colectiva, 6 (2), 137.

Lemieux, P. (2015). The dangers of "public health»: What was once a concern about public goods has transformed into a social crusade with a political agenda. Regulation, 38 (5), 30-35.

Lozada Pimiento, N. (2006). En torno al régimen de contratación de las empresas sociales del Estado. Revista de Derecho del Estado, 18, 153170.

Martínez Lillo, P. y Rubio Apiolaza, P. (2016). Del neoliberalismo conservador al giro a la izquierda: el discurso político latinoamericano en la era global, 1990-2010. En Martínez Lillo, P. y Estefanía, J. (Eds.), América Latina. Un nuevo contrato social. Madrid: Marcial Pons.

Medici, A. (2004). Seguros públicos de salud en América Latina: ¿Cuáles son las perspectivas? En Sánchez de León, A. (Ed.), Seguro Público de Salud. Aportes para un debate abierto. Rosario: Instituto de la Salud Juan Lazarte.

Meilán Gil, J. L. (2018). El contrato público determinado por el interés general. Revista de la Facultad de Derecho de México, 68 (271), 669-705.

Meneu, R. y Urbanos, R. (2018). La colaboración público-privada en sanidad: Hasta dónde y cómo delimitar sus fronteras. Cuadernos Económicos de ICE, 96, 35-56.

Mesa-Lago, C. (2005). Las reformas de salud en América Latina y el Caribe: su impacto en los principios de la seguridad social. Disponible en ttps:// repositorio.cepal.org/bitstream/handle/11362/3888/S2005077_ es.pdf [29-02-2020].

Ministerio de Salud (2017). Informe sobre brechas de personal de salud por servicio de salud. Recuperado de https://www.minsal.cl/wpcontent/uploads/2015/08/Informe-Brechas-RHS-en-Sector-Público_ Abril2017.pdf [29-02-2020].

. (2018). Unidad de Gestión Centralizada de Camas, UGCC. Disponible en https://www.minsal.cl/wp-content/uploads/2018/03/ Informe-UGCC-2014-2018.pdf [29-02-2020]. 
Moraga Klenner, C. (2019). Contratación Administrativa. Santiago: Thomson Reuters.

Moraga Cortés, F., Bahía Coelho, T. y Prada Sanabria, C. (2018). Trayectoria histórica del sistema de salud chileno: antecedentes para entender el actual esquema de financiamiento. Ponencia presentada en la Convención Internacional de Salud Pública Cuba Salud 2018, 23 al 27 de abril, La Habana, Cuba. Disponible en http://convencionsalud2018. sld.cu/index.php/connvencionsalud/2018/paper/view/787/180 [2902-2020].

Moreo Marroig, T. (2018). El futuro de la contratación pública sanitaria. Presupuesto y Gasto Público, 93, 93-115.

Muñoz Machado, S. (2017). Diccionario Panhispánico del español jurídico. Madrid: Santillana Educación, S.L.

(2018). Tratado de Derecho Administrativo y de Derecho Público General. XIII Contratos del Sector Público. Madrid: Boletín Oficial del Estado.

Organización para la Cooperación y Desarrollo Económicos (OCDE) (2017). Estudios de la OCDE sobre los Sistemas de Salud: Costa Rica. Evaluación y recomendaciones. Disponible en https://www.oecd.org/els/ health-systems/Estudios-OCDE-sobre-los-Sistemas-de-Salud_CostaRica_Evaluación-y-Recomendaciones.pdf [29-02-2020].

Oliva Moreno, J., González López-Valcárcel, B., Trapero Bertrán, M., Hidalgo Vega, A. y del Llano Señarís, J. (2018). Economía de la salud. Madrid: Pirámide.

Organización Mundial de la Salud (OMS) (2000). Informe sobre la Salud en el mundo 2000. Mejorar los sistemas de salud. Disponible en https:// www.who.int/whr/2000/en/whr00_es.pdf?ua=1 [29-02-2020].

. (2005). OMS ¿Qué es un sistema de salud? Disponible en https://www.who.int/features/qa/28/es/ [29-02-2020].

Organización Panamericana de la Salud (OPS) (2010). Redes integradas de servicios de salud: Conceptos, opciones de politica y hoja de ruta para su implementación en las Américas. Disponible en https://www.paho.org/ uru/index.php?option=com_docman\&amp;view=download\&amp;ali as=145-redes-integradas-de-servicios-de-salud-aps-n4\&amp;category_ 
slug=publicaciones-sistemas $-y$-servicios-de-salud \&amp;Itemid $=307$ [29-02-2020].

Parejo, L. (2004). Servicios públicos y servicios de interés general: La renovada actualidad de los primeros. Revista de Derecho de la Unión Europea, 7 (2), 51-68.

Pereira Barboza, E. (2017). Los caminos para la salud publica en Brasil. Disponible en https://www.easp.es/blogmsp/2017/11/03/los-caminospara-la-salud-publica-en-brasil/ [29-02-2020].

Pérez Gálvez, F. (2015). La sostenibilidad del sistema nacional de salud. En Pérez Gálvez, F. (Ed.), La sostenibilidad del sistema nacional de salud. Granada: Comares.

Perrot, J. (2006a). Different approaches to contracting in health systems. Bulletin of the World Health Organization, 84 (11), 859-866.

. (2006b). Is contracting a form of privatization? Bulletin of the World Health Organization, 84 (11), 910-911.

Programa de Naciones Unidas para el Desarrollo (PNUD) (2018). Desigualdad regional en Chile. Ingresos, salud y educación en perspectiva territorial. Santiago: PNUD.

Plataforma de información para políticas públicas de la Universidad Nacional de Cuyo (PIPP) (2011). Caracterización de Modelos Sanitarios y Sistemas Sanitarios. Disponible en http://www.politicaspublicas. uncuyo.edu.ar/articulos/index/caracterizacion-de-modelos-sanitariosy-sistemas-sanitarios [29-02-2020].

Prudencio Gamio, S. (2011). ¿Qué se requiere realmente para contar con compras gubernamentales más eficientes? ¿Basta con modificaciones normativas? Una mirada a los procesos de selección sujetos a la legislación de contrataciones del Estado. Revista de Derecho PUCP, 66, 131-145.

Raczynski, D. (1983). Reformas al sector salud. Colección Estudios CIEPLAN, 10, 5-43.

Reichard, S. (1996). Ideology drives health care reforms in Chile. Journal of Public Health Policy, 17 (1), 80-98. 
Repullo Labrador, J. (2014). Sistemas sanitarios y reformas: dimensiones, escenarios y patrones. En Repullo Labrador, J. (Ed.), Gestión sanitaria para la calidad y la excelencia. Madrid: Ediciones Díaz de Santos.

Rivera Jiménez, V., Vargas Aldana, E. y Moreno Casasbuenas, R. (2017). Descripción de las interrelaciones entre actores y funciones del sistema general de seguridad social en salud colombiano: una mirada desde el derecho fundamental a la salud. Trabajo de grado para optar al título de Magíster en Administración en Salud, Universidad de Rosario, Colombia. Disponible en https://repository.urosario.edu.co/ bitstream/handle/10336/13353/RiveraJimenez-VivianaPaola-2017. pdf?sequence $=8 \&$ amp;isAllowed $=y$ [20-02-2020] .

Rodríguez, M. (2019). El sector público y el sector privado de la sanidad: ¿Estabilidad o cambio? Gaceta Sanitaria, 33 (6), 499-501.

Rojas Calderón, C. (2018). Los servicios privados de interés público con motivo del Dictamen CGR No 11.718-2018. El Mercurio, 25 de mayo. Disponible en https://www.elmercurio.com/Legal/Noticias/ Opinion/2018/05/25/Los-servicios-privados-de-interes-publico-conmotivo-del-Dictamen-CGR-N-117182018.aspx [29-02-2020].

Sáenz, M., Acosta, M., Muiser, J. y Bermúdez, J. (2011). Sistema de salud de Costa Rica. Revista de Salud Pública de México, 53 (2 supl), 156167.

Salas, O. (2017). Cuasi mercado y privatización en el marco del Estado de bienestar de Suecia. Revista del CLAD Reforma y Democracia, 69, 191-222.

Sánchez de León, A. (2004). La función de compra de servicios de salud en el marco del seguro público de salud de la provincia de Buenos Aires. En Sánchez de León, A. (Ed.), Seguro Público de Salud. Aportes para un debate abierto. Rosario: Instituto de la Salud Juan Lazarte.

Sánchez-Martínez, F., Abellán-Perpiñán, J. y Oliva-Moreno, J. (2014). La privatización de la gestión sanitaria: Efecto secundario de la crisis y síntoma de mal gobierno. Informe SESPAS 2014. Gaceta Sanitaria, $28,75-80$.

Segovia, M. (2017). Carteles médicos, colusión y sobreprecios: el hoyo negro de la salud pública que revela el informe sobre Fonasa. El Mostrador, 16 de noviembre. Disponible en https:/www.elmostrador.cl/noticias/ 
pais/2017/11/16/carteles-medicos-colusion-y-sobreprecios-el-hoyonegro-de-la-salud-publica-que-revela-el-informe-sobre-fonasa/ [2902-2020].

Sojo, A. (2000). Cuasimercados y reformas de gestión en salud: Experiencias comparadas de Chile, Colombia, Argentina y Costa Rica. Santiago: CEPAL.

. (2001). Reformas de gestión en salud en América Latina. Revista de la CEPAL, 74, 139-157.

Superintendencia de Salud. (s. f.). Biblioteca digital. Disponible en https:// w3-channel.html [29-02-2020].

Torno Mas, J. (2016). El concepto de servicio público a la luz del derecho comunitario. Revista de Administración Pública, 200, 193-211.

Tribunal Constitucional. (2019). STC 18.01.2019, roles $N^{\circ} 5572$ y 56502018. Disponible en https://www.tribunalconstitucional.cl/ver2. php?id=4168 [29-02-2020].

Ugalde, A. y Homedes, N. (2005a). Las reformas de salud neoliberales en América Latina: Una visión crítica a través de dos estudios de caso. Revista Panamericana de Salud Pública, 17 (3), 210-220.

. (2005b). Las reformas neoliberales del sector de la salud: Déficit gerencial y alienación del recurso humano en América Latina. Revista Panamericana de Salud Pública, 17 (3), 202-209.

Veloso, L. (2020). Sistema público gastó más de \&\#36;550 mil millones en prestaciones privadas de salud durante 2019. Biobio, 13 de enero. Disponible en https://www.biobiochile.cl/noticias/nacional/ chile/2020/01/13/sistema-publico-gasto-mas-de-550-mil-millonesen-prestaciones-privadas-de-salud-durante-2019.shtml [29-02-2020].

Vergara, M. (2015). Propuesta de reformas a los prestadores públicos de servicios médicos en Chile: Fortaleciendo la opción pública. Revista Médica de Chile, 143 (2), 237-243.

Vilaça Mendes, E. (2013). Las redes de atención de salud. Brasilia: Organización Panamericana de la Salud. 
Villalobos Dintrans, P. (2016). Sistemas de financiamiento y aseguramiento de salud: Reformas y alternativas para Chile. Los casos de Australia, Alemania, Holanda, Corea del Sur y Reino Unido. Disponible en http://www.supersalud.gob.cl/documentacion/666/articles-14790_ recurso_1.pdf [01-06-2020].

Villar Rojas, F. (2020). Los modelos de gestión de los servicios sanitarios en España. En A. Angulló Agüero y Marco Peñas, E. (Eds.), Financiación de la sanidad. Tributación, gestión, control del gasto y reparto constitucional del poder financiero. Valencia: Tirant Lo Blanch.

Wendt, C., Frisina, L. y Rothgang, H. (2009). Healthcare system types: A conceptual framework for comparison. Social Policy \& Administration, $43(1), 70-90$.

Zúñiga Fajuri, A. (2007). Sistemas sanitarios y reforma AUGE en Chile. Acta Bioethica, 13 (2), 237-245.

. (2010). Una teoría de la justicia para el cuidado sanitario: La protección de la salud en la constitución después de la reforma AUGE. Revista de Derecho (Valdivia), 23 (2), 113-130.

(2011). Teorías de la justicia distributiva: una fundamentación moral del derecho a la protección de la salud. Convergencia, 18 (55), 191-211.

\section{Normas citadas}

Constitución Política de la República de Chile, 24 de octubre de 1980.

Decreto con Fuerza de Ley $\mathrm{N}^{\circ}$ 1, fija texto refundido, coordinado y sistematizado del Decreto Ley $\mathrm{N}^{\circ} 2.763$, de 1979 y de las Leyes $\mathrm{N}^{\circ}$ 18.933 y N $^{\circ} 18.469,24$ de abril de 2006.

Decreto con Fuerza de Ley $\mathrm{N}^{\circ} 36$, del Ministerio de Salud, normas que se aplicarán en los convenios que celebren los servicios de salud, 27 de diciembre de 1980 .

Ley $\mathrm{N}^{\circ}$ 15.076, Estatuto para los médicos-cirujanos, farmacéuticos o químicos-farmacéuticos, bioquímicos y cirujanos dentistas, 15 de enero de 1963.

Ley $\mathrm{N}^{\circ} 19.650$, perfecciona normas del área de la salud, 24 de diciembre de 1999. 
Ley $\mathrm{N}^{\circ} 19.664$, establece normas especiales para profesionales funcionarios que indica de los servicios de salud y modifica la Ley $\mathrm{N}^{\circ} 15.076,11 \mathrm{de}$ febrero de 2000.

Ley $\mathrm{N}^{\circ} 19.886$, Ley de bases sobre contratos administrativos de suministro y prestación de servicios, 30 de julio de 2003.

Ley $\mathrm{N}^{\circ}$ 19.966, establece un régimen de garantías en salud, 30 de septiembre de 2004.

Ley $\mathrm{N}^{\circ}$ 21.053, Ley de presupuestos del sector público para el año 2018, 27 de diciembre de 2017.

Resolución Exenta No 368 de la Subsecretaría de Redes Asistenciales, aprueba nuevo texto norma general administrativa No 2 sobre atención de pacientes particulares, 12 de febrero de 2010.

JURISPRUDENCIA CITADA

Dictamen de la Contraloría General de la República N46.126, 29 de septiembre de 2006.

Dictamen de la Contraloría General de la República N51.081, 27 de octubre de 2006.

Dictamen de la Contraloría General de la República N³8.109, 22 de agosto de 2007.

Dictamen de la Contraloría General de la República N 59.990, 18 de diciembre de 2008.

Dictamen de la Contraloría General de la República N44.822, 25 de julio de 2012.

Dictamen de la Contraloría General de la República: $N^{\circ} 11.781,9$ de mayo de 2018.

Dictamen de la Contraloría General de la República N²4.216, 27 de septiembre de 2018.

Recibido: 09-02-2020

Aceptación de la versión final: 01-06-2020 